\title{
The Role of the Biomechanics Expert in Evaluating a Criminal Case of Vehicle Assault: A Case Study Addressing Fraud
}

\section{Patrick Hannon*}

Emeritus Faculty, Northern Arizona University, Department of Biology, USA

*Corresponding author: Patrick Hannon, Department of Biology, Northern Arizona University, USA, Tel: 480-816-0930; E-mail: Hannon@hannonbiomechanics.com

Received date: May 27, 2016; Accepted date: May 30, 2016; Published date: June 06, 2016

Copyright: (c) 2016 Hannon P. This is an open-access article distributed under the terms of the Creative Commons Attribution License, which permits unrestricted use, distribution and reproduction in any medium, provided the original author and source are credited.

\section{Editorial}

This case involved two couples who lived and worked in a rural area. They were employed by the same company and shared the same work pickup truck during different work shifts. Grievances and animosity had developed between the two parties and therefore motivation to "get even" could be ascribed to both parties. One afternoon, the husband of one of the couples claimed that as he was walking to his mailbox, the female of the other couple purposely drove the company pickup truck off the road striking him and leaving him incapacitated for a period of time. He recalled that the female was smiling as she drove into him and then remembered her driving to and parking in the vehicle exchange spot near his house. The accused female perpetrator was allegedly then picked up by her boyfriend and the two drove away from the area.

According to the victim, he was finally able to get back to his house and wife after his head injury some time later (a distance of approximately $50 \mathrm{yds}$ ). The alleged victim's wife called 911, and EMT personnel and the local police came to the house. The alleged victim was described as dazed by EMT personnel, was given narcotic medication for pain (with improvement in mentation) and was taken to a local hospital ER for examination while his wife was questioned by the police. The police followed up with a discussion with her husband at the hospital.

Soon after, the alleged victim was released from the hospital with a diagnosis of a possible concussion and several abrasions/contusions to his abdomen, chest, forearms, elbows and lower extremities. The objective evidence evaluation of more serious injury included a description of a traumatic head/face (without deformity), a GCS of 15 and a negative CT scan of the head/brain. The accused female driver was then put under arrest later that night.

The physical evidence collected included:

1) Damage to the subject driver's side pickup truck hood.

2) A wrist watch with a broken band at the alleged scene belonging to the alleged victim.

3) Tire marks going off the road which matched the pickup truck.

4) A dusty footprint found on top of driver's side front bumper later determined to match the shoe tread of the shoes that were worn by the alleged victim on the day of the incident.

Furthermore, the police department detectives also later provided a video reenactment with the alleged victim indicating how he was struck by the pickup truck.

The principal question posed by the criminal defense attorneys to me was: Was this an intentional hit and run collision or a staged fraudulent pedestrian strike? Our analysis included the following findings:

1. This incident was a staged pedestrian strike. The injuries of the alleged victim were most probably accomplished by a relatively slow run followed by head first (i.e. baseball slide (s) into the dirt/small rock ground surface (at the scene or at the residence). He kept his head-face up so as to avoid facial injury. However, the head first slide on the ventral surface of his body was a match for the minor superficial abrasions on his left anterior-lateral shank (calf), left side abdomen, and a small area of the left upper chest. Small abrasions also occurred to the surfaces of both his upper (proximal) forearms consistent with his attempt to minimize abrasion injury to his face. His long sleeve shirt reduced the depth of these abrasions consistent with the fact that during his slide(s), the vast majority of the abrasions did not enter below the skin's epidermis layers. The abrasions that did exist upon his body were in one direction, parallel to each other and lined up with the body's long axis with no evidence of tumbling on the ground surface. Days later, some police photographs indicated small areas of bruising upon the chest and abdomen.

2. A pedestrian strike was also inconsistent with the alleged victim's previous incident descriptions and/or recorded statements. Furthermore, serious injury would occur to one or both lower extremities in the area of the superior tibia/fibula, knee or thigh as the result of a vehicle bumper strike. Injury biomechanics dictate that underlying tissues such as muscle will develop significant hematoma from such a vehicle strike and long bones may fracture via a three point bending mechanism. The ankle joint and the subtalar joint (foot) may dislocate with or without bone fractures. In this regard, it was noted that objective medical trauma measures were limited to only small areas of superficial skin damage to the lower extremities of the alleged victim.

3. The wrist watch band was not the type of band that would normally come apart during a vehicle-pedestrian collision and furthermore, neither of the wrists of the alleged victim showed any signs of trauma.

4. The dent deformation pattern on the left hood panel was not consistent with a head strike and there was no damage to the front of the pickup truck at the supposed strike point. Furthermore, my viewing of the actual head CT scan indicated no evidence of SCALP trauma, a finding that was inconsistent with the alleged victim's claim of his head striking the hood and rendering him unconscious. Instead our analysis indicated that this individual had climbed up onto the bumper/hood and had dropped a heavy load onto the vehicle in an area where he thought a pedestrian's head should strike the hood panel. Our opinion was consistent with our momentum/force/ deformation analysis of the hood dent. 
Citation: Hannon P (2016) The Role of the Biomechanics Expert in Evaluating a Criminal Case of Vehicle Assault: A Case Study Addressing Fraud . J Forensic Biomed 7: e110. doi:10.4172/2090-2697.1000e110

Page 2 of 2

Again, this case illustrates the value of a biomechanics expert to the trier of fact. In this criminal case, a team approach involving physical evidence experts and a biomechanics expert were able provide a strong defense for the accused resulting in a dismissal of all charges against the defendant. 